\title{
Subsidence of rice paddy and upland crop fields in Shinotsu Peatland, Hokkaido, Japan
}

\author{
Minoru Yokochi ${ }^{1}$, Koichi Sekimoto ${ }^{2}$, and Takashi Inoue ${ }^{3,4}$ \\ ${ }^{1}$ Graduate School of Global Food Resources, Hokkaido University, Sapporo, Japan \\ ${ }^{2}$ Graduate School of Agriculture, Hokkaido University, Sapporo, Japan \\ ${ }^{3}$ Research Faculty of Agriculture, Hokkaido University, Sapporo, Japan \\ ${ }^{4}$ Global Station for Food, Land and Water Resources, GI-CoRE, Hokkaido University, Sapporo, Japan \\ Correspondence: Minoru Yokochi (mino_violalala@eis.hokudai.ac.jp)
}

Published: 22 April 2020

\begin{abstract}
Agricultural land use on peatlands inevitably causes ongoing land surface subsidence resulting in a reduction of productivity. In addition, oxidation of the peat substrate associated with subsidence is responsible for greenhouse gas emission with the ensuing consequence for global climatic stability. A concept of "paludiculture", the utilisation of wet or rewetted peatlands for agriculture, has been proposed in European countries to avoid further subsidence and greenhouse gas emission. However, few studies have documented a long-term record of subsidence through agriculture in wet peatlands such as paddy fields for rice cultivation. In this study, we measured the subsidence rates of peatland in rice paddy use and compared them to the rates in peatland with upland crop cultivation. The average subsidence between 2006 and 2016 for the paddy plots was $3.6 \pm 1.9 \mathrm{~cm}$ $( \pm \mathrm{SE}$ ) and significantly less than that of $25.6 \pm 1.7 \mathrm{~cm}$ for the upland plots, and the subsidence reduced linearly as the period of paddy use increased. These results suggest that paddy use of peatlands can effectively reduce subsidence. Our results will encourage the use of peatlands with a wet environment as one of the valid options for future peatland management in terms of mitigation of land subsidence and peat loss.
\end{abstract}

\section{Introduction}

Drainage and land reclamation for agricultural use of peatlands inevitably causes ongoing land surface subsidence. Many examples of subsidence thorough agricultural use of peatlands have been reported all over the world (Leifeld et al., 2011; Pronger et al., 2014; Schipper and McLeod, 2006; Zanello et al., 2011). Subsidence in reclaimed farmlands often lead to social, economic, and environmental troubles including reduction of agricultural productivity due to relative groundwater level rise, increased risks of inundation combined with sea-level rise (Zanello et al., 2011), and increased cost to maintain farmland productivity (Gambolati et al., 2006; Wösten et al., 1997). Additionally, drained boreal peatlands are estimated to be causing more than $0.0085 \mathrm{Pg} \mathrm{yr}^{-1}$ of carbon emission through oxidation process of peat substrate (Gorham, 1991), with ensuing indispensable consequences to global climate stability (Parish et al., 2008). Without appropriate management, not only will the agricultural economic value of cultivated peatlands be lost, but also the whole society will be adversely affected by the subsidence related problems. Hence, appropriate land use management on agricultural peatlands is strongly required.

Recently several techniques of land use management on cultivated peatlands has been proposed to mitigate further subsidence and greenhouse gas emission. Higher groundwater level generally reduces decomposition of peat substrate, and therefore, maintenance of high water table with rewetting and submerged infiltration of water has been regarded as a promising option (Hendriks et al., 2007). Paludiculture, the agricultural use of wet or rewetted peatlands mainly for biomass production, has been discussed as a solution to the subsidence related problems in peatlands. It may effectively reduce the decomposition of organic material and, is acknowledged as a possible land use option on organic soils. However, few studies have documented long-term records of peat subsidence and peat loss through agriculture in wet 


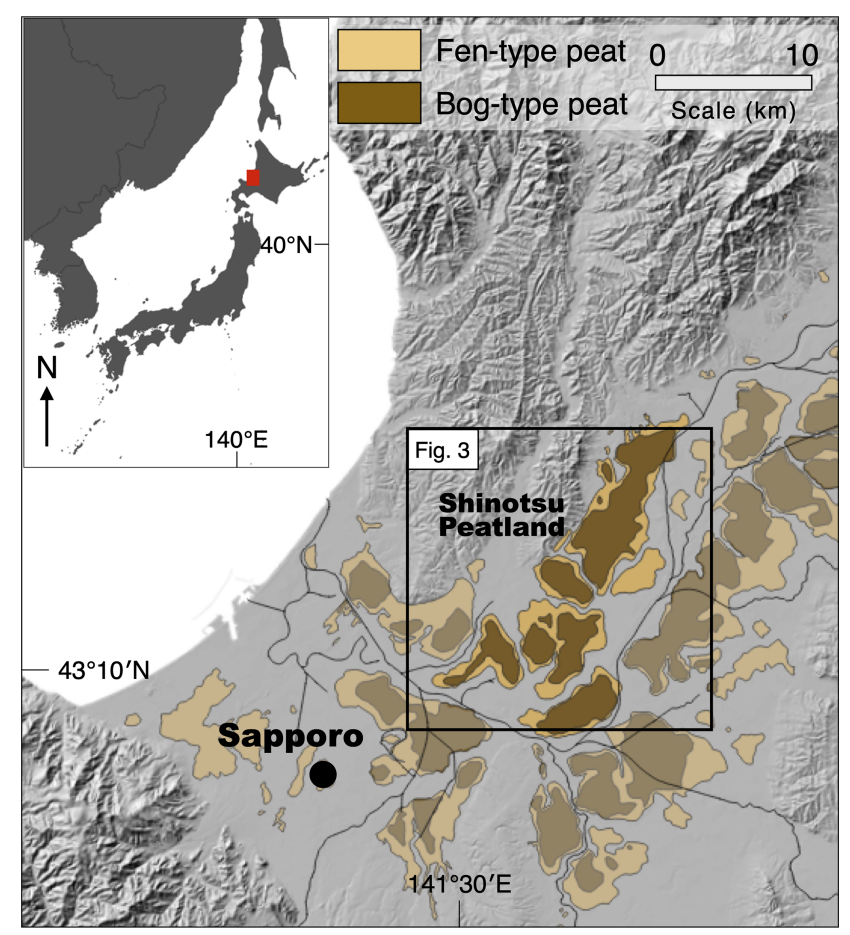

Figure 1. Location and extent of the study site and peatland area in Shinotsu, Hokkaido. The background shaded-relief map is obtained from Geospatial Information Authority of Japan. The distribution of peat is based on Hokkaido Agricultural Reserch Institution (1954). An inset map in the upper left corner shows the location of the study site within Japan.

peatlands because the implementation of paludiculture has evolved only in recent years.

In Hokkaido, northern Japan, peatlands have been used as multi-use paddy fields (rotational cultivation of paddy rice and upland crop), one form of palidiculture, for more than a half-century. In paddy fields, the groundwater table maintains near the ground surface or above during the summer irrigation period, so the subsidence in paddy is expected to slow due to reduction of decomposition of peat substrate. Some studies, indeed, suggested the possibility of the lower rate of peat subsidence in paddy fields compared to upland fields in Hokkaido (Kasubuchi et al., 1998; Miyaji et al., 1995), yet the number of observation in those studies was not sufficient to statistically conclude.

Here, we present the first quantitative comparison of the long-term peat subsidence rates between paddy and upland fields in Hokkaido to assess the potential of agricultural use of wet peatlands as a solution of peat subsidence-related problems. This study will provide an essential suggestion for future land use in Hokkaido and also key knowledge for the attempt of the paludicultural use of peatlands worldwide as well.

\section{Materials and methods}

\subsection{Reginal settings}

The investigation of peat subsidence was conducted in Shinotsu Peatland (Fig. 1; $43^{\circ} 15^{\prime} \mathrm{N}, 141^{\circ} 18^{\prime}$ E), central Hokkaido, Japan. Its total area is about 12000 ha, and currently, almost all area has been converted into cultivated land. The mean annual temperature is $7.0^{\circ}$, and the mean annual precipitation is $1105 \mathrm{~mm}$ with $816 \mathrm{~cm}$ of snowfall at ShinShinotsu Weather Station of Japan Meteorological Agency. Currently, peat deposited 6 to $7 \mathrm{~m}$ thick. The both of bogtype peat and fen-type peat are distributed all over the area, and generally, the fen-type peat is surrounding the bog-type peat.

The peatland has been cultivated as multi-use paddy fields (rotational cultivation of paddy rice and upland crop) (Fig. 2), and the main crops in this area are currently paddy rice, wheat, soybean, and vegetables. Initially, the area converted to paddy, but the area that is producing upland crop such as wheat have been increasing under the situation of overproduction of rice and the implementation of the set-aside policy by the national government since 1971. In the paddy fields, the ground surface is always saturated with irrigation water between middle May and middle August. Both of the paddy and the upland fields has drainage ditches and subsurface drainage systems to maintain a suitable groundwater table for the crops, so either paddy rice and upland crops can be grown by the combination of irrigation and drainage systems.

\subsection{Subsidence measurement}

Digital elevation models (DEMs) which constructed by airborne laser survey were employed for measurement of subsidence. The spatial resolution of the DEMs was $1 \mathrm{~m} \times 1 \mathrm{~m}$. The total subsidence between 2006 and 2016 in each point was calculated by subtracting the DEM of 2016 from the DEM of 2006 using GIS software (QGIS). For each filed plot, the values of the total subsidence were averaged for the analysis. The DEM of 2006 has an error due to vegetation height in some field plots, so those plots were excluded from the analysis. We used randomly selected 53 field plots for the analysis to assess the effect of the land use form (paddy or upland) on peat subsidence. The 53 filed plots belonged to the same township, and the conditions such as the time since reclamation and the peat type were not different except the land use form.

\subsection{Reconstruction of the history of land use form}

We reconstructed the land use form of the 53 field plots for each year between 2006 and 2016 to examine the relationship between the peat subsidence and the land use form. We used satellite images which were taken by the optical sensor to assess the land use form of each year. The satellite 


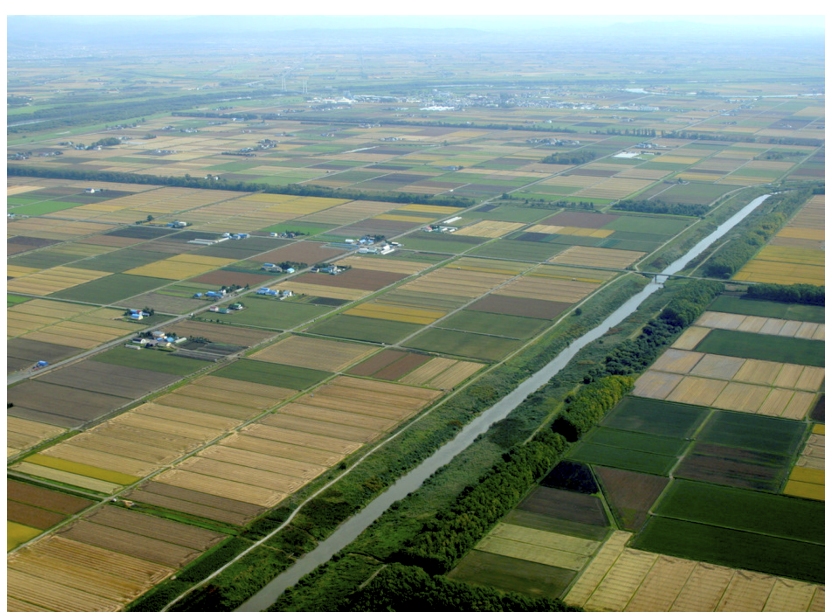

Figure 2. An aerial photograph of multi-use cultivated fields with a canal for irrigation and drainage in Shinotsu Peatland.

included Landsat-5 TM, Landsat-8 TM, and Sentinel-2. We employed the bands of visible red (R), near-infrared (NIR), and short-wave infrared (SWIR). The reflection of each band of the electric wave on the ground surface varies depending on the land cover because each land cover has different spectral reflection characteristic. Water can absorb all bands, so reflectance of R, NIR and SWIR are generally low. The plant vegetation highly reflects NIR, but less for R and SWIR. Soil can highly reflect SWIR, but less for R and NIR. During the rice transplanting period (May to early June), the paddy fields are filled by irrigation water whereas the upland fields are covered by vegetation or bare lands. Based on the land covered difference, we distinguished the land use forms using a colour composited image of the R, NIR, and SWIR bands (Fig. 3). This remote sensing technique is often used in crop classification (Liu et al., 2005). We reconstructed the land use form in the 53 field plots between 2006 and 2016, excluding 2007, 2011, and 2012 in which the satellite images were not available due to cloud cover.

\section{Results and Discussion}

As a result of the reconstruction of the history of the land use form, 12 field plots out of the 53 plots were used as paddy for 7 years or more between 2006 and 2016 (referred to herein as the "paddy"), and 15 plots were used as upland fields for 7 years or more ("upland"). The rest 26 plots were for rotational use of paddy and upland ("rotation"). In the rotation plots, rotation of paddy rice and upland crops were generally conducted every 3 or 4 years.

The relationship of the peat subsidence to the crop rotation was examined in 53 fields. The overall mean of the subsidence from 2006 to 2016 in the 53 fields was $15.8 \mathrm{~cm}$, which equals to $15.8 \mathrm{~mm} \mathrm{yr}^{-1}$. The total subsidence from 2006 to 2016 was plotted against the year which each field

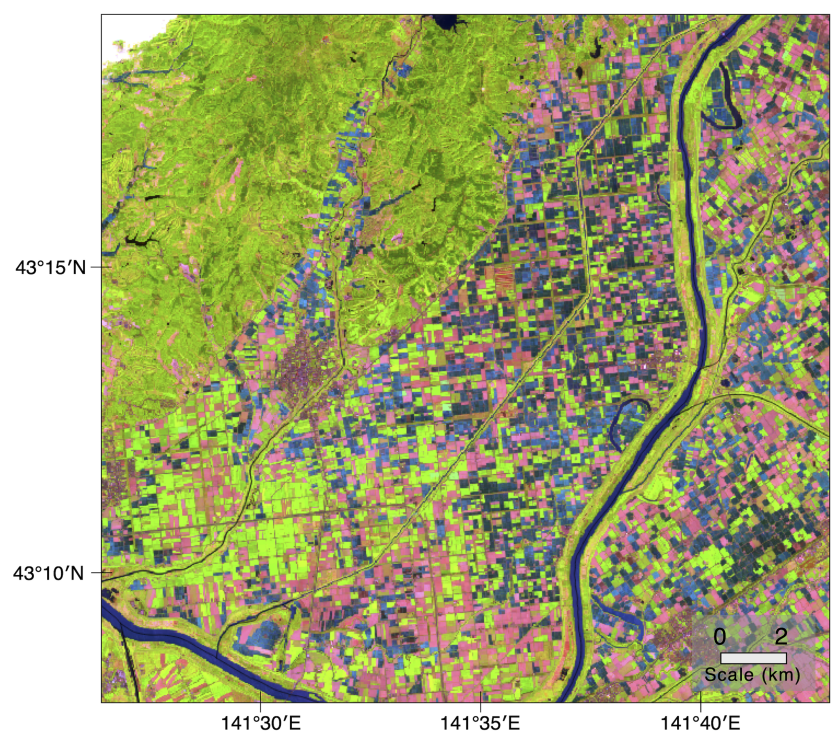

Figure 3. Color composited satellite image of bands of red (R), near-infrared (NIR) and short-wave infrared (SWIR), of Sentinel-2 taken on 28 May 2016 covering Shinotsu Peatland. RGB $=($ SWIR, NIR, R). Green area, pink area, and blue area represent upland fields with vegetation, upland fields with no vegetation, and paddy fields, respectively.

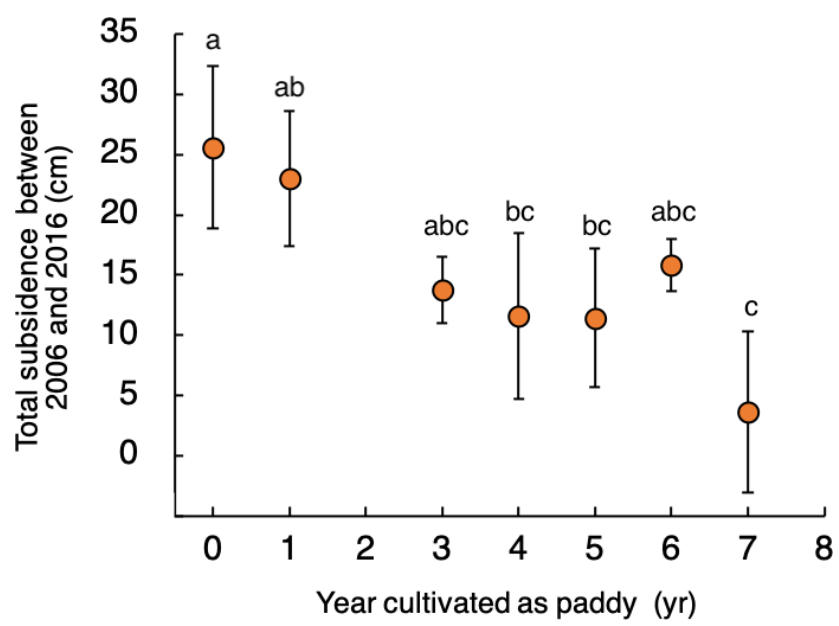

Figure 4. Relationship between total subsidence from 2006 to 2016 and the years that each field was used as paddy field (out of eight years which the satellite image is available). The error bars represent the standard deviation of the samples. The plots with the same letter are not significantly different in the Tukey-Kramer test $(p<0.05)$.

was used for rice paddy in the same period (excluding 2007, 2011, and 2012, in which satellite images were not available) (Fig. 4). The mean subsidence was $3.7 \pm 1.9 \mathrm{~cm}( \pm \mathrm{SE}$; $n=12$ ) for 11 years in the paddy field plots, and significantly less than the rate of $25.6 \pm 1.7 \mathrm{~cm}(n=15)$ in upland field plots $(p<0.001)$. In the rotation field plots, the subsidence was intermediated value between the paddy and the upland 
plots, although the difference was not statistically significant level $(p>0.05)$ in the Tukey-Kramer multiple comparisons. Still, it was clear there was a trend that the subsidence reduced linearly as the period of paddy increased. This result suggested that paddy use of peatlands could effectively reduce the rate of peat subsidence.

The total subsidence in the paddy plots was significantly smaller than that of the upland field plots. The average subsidence rate of $3.7 \mathrm{mmyr}^{-1}$ in the paddy plots was extremely low value compared with globally reported values of the peat subsidence through agricultural exploitation (Pronger et al., 2014). Whereas, the average subsidence rate of $25.6 \mathrm{~mm} \mathrm{yr}^{-1}$ in the upland plots was well consistent with the globally reported values. These values also showed that the peat subsidence through wet agricultural use was smaller than the through upland use.

The possible reason for the reduction of subsidence in the paddy may have been high groundwater table which inhibits oxidation of peat substrate. Previous studies have reported that high groundwater table reduced decomposition of peat substrate (Hendriks et al., 2007; Kim and Verma, 1992). In the paddy plots, the water table was always maintained above the ground surface in cultivate period in summer, which kept the peat layer in anaerobic condition. Although the groundwater is drained and lowered from autumn to early spring, the temperature is generally low, and much snowfall occurs in those periods without irrigation, which restrains the microbe activity of the decomposition of the peat. This implies that the maintenance of wet condition only in the summer season can sufficiently reduce peat subsidence.

In this study, we just compared the subsidence in the paddy and upland fields by measuring elevation change in the specific period and did not examine the decomposition rate, the greenhouse gas emission, and their temporal trends. Thus, the mechanism of the reduction of the subsidence in the paddy fields has still not been cleared. Additionally, few studies have reported subsidence on paddy peatland. More studies on subsidence in paddy fields are required to clarify the mechanism and to reinforce our argument. Also, though our results showed the rice paddy has a lower impact on peat subsidence, the demand and consumption of rice have been continuously decreasing in Japan. Not only technical implementations but also political and economic intervention is necessary to achieve sustainable land use management on the peatlands.

\section{Conclusions}

We calculated the subsidence rates in different agricultural land use form, i.e., rice paddy or upland field. The subsidence rate in the rice paddy had significantly lower than that in the upland field. This difference suggested that paddy land use had a lower impact on peat subsidence. Our results will encourage the agricultural use of wet or rewetted peatlands as one of the valid options for future peatland management in terms of mitigation of land subsidence and peat loss.

Data availability. The DEM data used in this study were provided from Hokkaido Development Bureau. The DEM data are not publicly opened due to national security. The satellite image data are available from the website of U.S. Geological Survey (https://landsatlook.usgs.gov, U.S. Geological Survey, 2020). The processed data of the subsidence for the analysis are available from the corresponding author, up on reasonable request.

Author contributions. MY and TI developed the overall concept and methodology of the study. KS processed the satellite images. MY processed the DEM data and conducted the statistical data analysis. MY prepared the manuscript with contribution from all coauthors.

Competing interests. The authors declare that they have no conflict of interest.

Special issue statement. This article is part of the special issue "TISOLS: the Tenth International Symposium On Land Subsidence - living with subsidence". It is a result of the Tenth International Symposium on Land Subsidence, Delft, the Netherlands, 17-21 May 2021.

Acknowledgements. We express our sincere thanks to Shinotsu Chuo Land Improvement District (Farmers' water use association) and Hokkaido Development Bureau for providing us airborne laser survey data. This study was funded by the Land Improvement Construction Association of Japan, and we appreciate their grateful support.

Financial support. This research has been sponsored by Land Improvement Construction Association of Japan.

\section{References}

Gambolati, G., Putti, M., Teatini, P., and Gasparetto Stori, G.: Subsidence due to peat oxidation and impact on drainage infrastructures in a farmland catchment south of the Venice Lagoon, Environ. Geol., 49, 814-820, https://doi.org/10.1007/s00254-0060176-6, 2006.

Gorham, E.: Northern Peatlands: Role in the Carbon Cycle and Probable Responses to Climatic Warming, Ecol. Appl., 1, 182195, https://doi.org/10.2307/1941811, 1991.

Hendriks, D. M. D., van Huissteden, J., Dolman, A. J., and van der Molen, M. K.: The full greenhouse gas balance of an abandoned peat meadow, Biogeosciences, 4, 411-424, https://doi.org/10.5194/bg-4-411-2007, 2007. 
Hokkaido Agricultural Reserch Institution: Soil Texture Report 4, Soil texture in Ishikari, Sapporo, 1954.

Kasubuchi, T., Yoshida, C., Kudo, S., and Miura, K.: Prevention of peat subsindece in enlarged paddy fields and cycle irrigation, Water, land, Environ. Eng., 66, 177-182, doi:https://doi.org/10.11408/jjsidre1965.66.2_177, 1998.

Kim, J. and Verma, S. B.: Soil surface CO2 flux in a Minnesota peatland, Biogeochemistry, 18, 37-51, https://doi.org/10.1007/BF00000425, 1992.

Leifeld, J., Müller, M., and Fuhrer, J.: Peatland subsidence and carbon loss from drained temperate fens, Soil Use Manage., 27, 170-176, https://doi.org/10.1111/j.1475-2743.2011.00327.x, 2011.

Liu, J., Liu, M., Tian, H., Zhuang, D., Zhang, Z., Zhang, W., Tang, X., and Deng, X.: Spatial and temporal patterns of China's cropland during 1990-2000: An analysis based on Landsat TM data, Remote Sens. Environ., 98, 442-456, https://doi.org/10.1016/j.rse.2005.08.012, 2005.

Miyaji, N., Kohyama, K., Hiroo, O., and Kasubuchi, T.: Surface Subsidenee of Peatland in Bibai, Central Hokkado, Japanese J. Soil Sci. Plant Nutr., 66, 465-473, 1995.

Parish, F., Sirin, A., Charman, D., Joosten, H., Minayeva, T., Silvius, M., and Stringer, L.: Assessment on Peatlands, Biodiversity and Climate change, available at: http://www.imcg.net/media/ download_gallery/books/assessment_peatland.pdf; (last access: 5 March 2020), 2008.
Pronger, J., Schipper, L. A., Hill, R. B., Campbell, D. I., and McLeod, M.: Subsidence Rates of Drained Agricultural Peatlands in New Zealand and the Relationship with Time since Drainage, J. Environ. Qual., 43, 1442, https://doi.org/10.2134/jeq2013.12.0505, 2014.

Schipper, L. A. and McLeod, M.: Subsidence rates and carbon loss in peat soils following conversion to pasture in the Waikato Region, New Zealand, Soil Use Manage., 18, 91-93, https://doi.org/10.1111/j.1475-2743.2002.tb00225.x, 2006.

U.S. Geological Survey: Landsat image, available at: https:// landsatlook.usgs.gov, last access: 5 March 2020.

Wösten, J. H., Ismail, A., and van Wijk, A. L. .: Peat subsidence and its practical implications: a case study in Malaysia, Geoderma, 78, 25-36, https://doi.org/10.1016/S00167061(97)00013-X, 1997.

Zanello, F., Teatini, P., Putti, M., and Gambolati, G.: Long term peatland subsidence: Experimental study and modeling scenarios in the Venice coastland, J. Geophys. Res.-Earth, 116, 1-14, https://doi.org/10.1029/2011JF002010, 2011. 